\title{
Comparison of Physical Parameters of the Individuals Who Have Received NASM-OPT Model \& EMS Training in Combination With Traditional Fitness Training Applications Regularly as Personal Training (PT) for 20 Weeks
}

\author{
Türker Bıyıklı \\ Correspondence: Türker Bıyıklı, Nisantasi University Physical Education and Sports School, İstanbul, Turkey.
}

Received: October 10, 2018

doi:10.11114/jets.v6i12.3673
Accepted: October 23, $2018 \quad$ Online Published: October 29, 2018

URL: https://doi.org/10.11114/jets.v6i12.3673

\begin{abstract}
In the study, it is aimed to determine whether there is any improvement in the physical performance development of the individuals, who have made exercise with OPT MODEL -EMS mix. and traditional PT models within the 20-week exercise program. In the study, pre-test, posttest, experimental screening by pattern methods are used. Study groups consist of 30 individuals, who are healthy and voluntary, continuing the fitness centers in Netherlands (OPT-EMS; n=30) and in Turkey (PT; $\mathrm{n}=30$ ). After the data obtained is entered in computer environment; the arithmetic means (X), standard deviations (ss) of the research groups are taken and the Paired Samples t-test is applied for the differences between the pre-test and posttest. Significance level is examined at $p<0.05$ level. When the study findings are examined, statistically significant differences are observed in the push-up, squat, crunch, plank and Max Vo2 performance measurements of the participants in 20-week OPT-EMS group $(\mathrm{p}<0.05)$. Also, a statistically significant difference is found in the left hand grip and plant test performance measurements of the participants in 20-week PT group $(\mathrm{p}<0.05)$.

As a result, the OPT model, which is an innovative approach and has five different training phases, and the continuation of training with EMG for a certain period of time can be said to contribute to the physical performance. In addition, in case PT training content is prepared according to the individual, it is considered that it will contribute to physical performance.
\end{abstract}

Keywords: OPT, NASM, PT, EMS, Traditional training

\section{Introduction}

With the improvements in technology and science, new training models, equipment and systems are in a continuous change, development and innovation. One of these innovative training methods is OPT model of NASM.

The OPT model was conceptualized as a training program for a society that has more structural imbalances and susceptibility to injury than ever before. It is a process of programming that systematically progresses any client to any goal. The OPT model Figure... is built on a foundation of principles that progressively and systematically allows any client to achieve optimal levels of physiologic, physical, and performance adaptations, including:

\section{A. Physiologic Benefits}

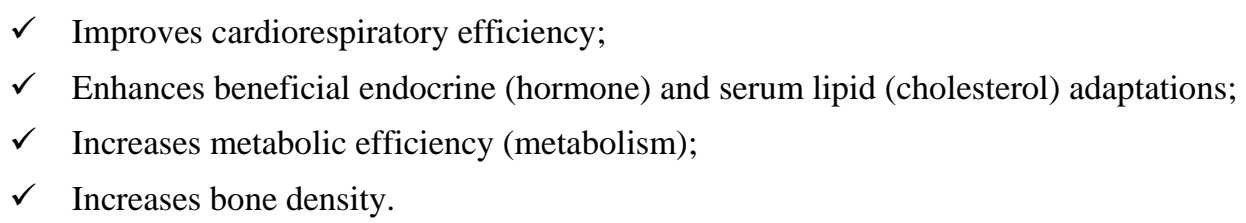

\section{B. Physical Benefits}

$\checkmark$ Decreases body fat;

$\checkmark$ Increases lean body mass (muscle);

$\checkmark$ Increases tissue tensile strength (tendons, ligaments, muscles). 


\section{Performance Benefits}

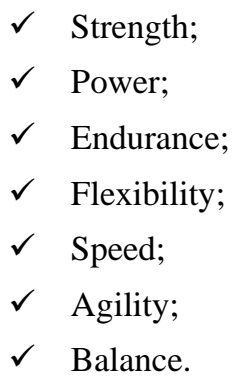

The OPT model is based on the scientific rationale of human movement science. Each stage has a designated purpose that provides the client with a systematic approach for progressing toward his or her individual goals, as well as addressing his or her specific needs.

One of the innovative training systems is Electromyostimulation (EMS) system. EMS, which was used for rehabilitation and treatment at the beginning, is started to be used in exercise and sports for performance-increasing purposes. EMS is an unconventional innovative training method used to obtain muscular activation via externally applied electrical currents to the muscle or the nerve regions and to achieve functional increases in sportive performance by training the fast motor units, which are hard to be activated voluntarily, via synchronous participation (Kaçoğlu and Kale, 2015). EMS is one of the methods that is frequently used in muscular strengthening and its effects continue to be relevant in clinical studies (Akt., Baskan2004, Vivodtzev 2006, Petterson 2006, Stackhouse 2007). Theoretically, the basis for using EMS in order to strengthen the muscles is to develop more motor unit action potential than maximal voluntary contraction (Akt., Rich 1992, Vrbova 2008). In other words, it is the realization of multiple contractions while contracting a muscle by EMS. Researches and studies regarding the usage and the popularity of EMS system in exercise and sports areas have increased and developed upon making a claim by the Russian researcher Yakov Kots in 1977 at a symposium at Concordia University regarding that contractions occurred by electrical currents create 10\%-30\% more isometric force than maximal voluntary contractions and EMS programs provide 30\%-40\% force increase in senior sportsmen (Vanderthommen and Duchateau, 2007). Based on the studies showing that EMS, applied during isometric muscular contractions without external resistance, provides significant increases in the cross sectional area of the muscle and in the maximal voluntary contraction force, its use becomes widespread for the purpose of developing sportive performance as a part of strength exercises regarding the increase in existing muscular strength in healthy individuals and of recovering the strength loss after a surgical intervention (Holcomb, 2006).

When this new and innovative model and system is considered, it is an issue of concern to see how important the combinations can play an important role in the development and increase of the basic and desired parameters in sportsmen and sedentaries.

In the direction of this information, in the study, it is aimed to determine whether there is any improvement in the physical performance development of the individuals, who have made exercise with OPT-EMS and PT exercise models within the 20-week exercise program.

\section{Method}

In the study, pre-test, posttest, experimental screening by pattern methods are used. Study groups consist of individuals continuing the fitness centers in Netherlands (OPT-EMS; n=30) and in Turkey (PT; n=30).

OPT-EMS Group: This group consists of the individuals continuing the Basic-Fit fitness center in Rotterdam, Netherlands for at least 1 year and making exercise for at least 2 days a week.

The study lasted four weeks at the beginning of the OPT Model training, and the respondents have not used any type of training or activity, which would affect the development of strength endurance of the lower and upper extremities.

Program of EMS was performed in the evening, twice a week, with Miha Bodytec II Model exercise apparatus. In a 4 week period, a total of 8 sessions were performed on selected muscle groups - quadriceps femoris and gastrocnemius for lower extremities and Pectoralis major, Rhomboids, latissimus dorsi and shoulder complex for upper extremities Program of Strength endurance training (28 min per session), for each muscle group were applied. High and low frequencies of stimulation was ( $>60 \mathrm{~Hz} v \mathrm{vs} .<15 \mathrm{~Hz}$ ), respectively inducing tetanic and non-tetanic contractions. 
1th.- 4th. Week: Stabilization Endurance,

Goals

Improve muscular endurance

Enhance joint stability

Increase flexibility

Enhance control of posture

Improve neuromuscular efficiency (balance, stabilization, muscular coordination)

Training Strategies

Training in unstable, yet controllable environments (proprioceptively enriched)

Low loads, high repetitions

GOAL: TOTAL BODY

PHASE: 1 STABILIZATION ENDURANCE

\begin{tabular}{|c|c|c|c|}
\hline \multicolumn{4}{|l|}{ WARM-UP } \\
\hline Exercise: & Sets & Duration & Coaching Tip \\
\hline SMR: Calves, IT-Band, Lats & 1 & $30 \mathrm{~s}$. & Hold each tender area for $30 \mathrm{sec}$ \\
\hline Static Stretch: Calves, Hip Flexors, Lats & 1 & $30 \mathrm{~s}$. & Hold each stretch for $30 \mathrm{sec}$ \\
\hline Treadmill & 1 & $5-10 \mathrm{~min}$ & Brisk walk to slow jog \\
\hline
\end{tabular}

\begin{tabular}{|l|c|c|c|c|c|}
\hline CORE / BALANCE / PLYOMETRIC & Sets & Reps & Tempo & Rest & Coaching Tip \\
\hline Exercise: & 2 & 12 & Slow & 0 & \\
\hline Floor Bridge & 2 & 12 & Slow & 0 & \\
\hline Floor Prone Cobra & 2 & 12 & Slow & 0 & \\
\hline Single-Leg Balance Reach & 2 & 5 & Slow & 90 s. & Holdlanding 3-5 seconds \\
\hline Squat Jump w/Stabilization &
\end{tabular}

\begin{tabular}{|l|l|l|l|l|}
\hline SPEED, AGILITY, QUICKNESS \\
\hline Exercise: & Sets & Reps & Rest & Coaching Tip \\
\hline Optional & & & & \\
\hline Optional & & & & \\
\hline
\end{tabular}

\begin{tabular}{|l|l|c|c|c|c|c|}
\hline RESISTANCE \\
\begin{tabular}{|l|l|c|c|c|} 
Exercise: \\
Total Body
\end{tabular} & Ball Squat, Curl to Press & 2 & 12 & Slow & 0 & Vertical loading \\
\hline Chest & Ball Dumbbell Chest Press & 2 & 12 & Slow & 0 & \\
\hline Back & Standing Cable Row & 2 & 12 & Slow & 0 & \\
\hline Shoulders & Single-Leg Dumbbell Scaption & 2 & 12 & Slow & 0 & \\
\hline Biceps & Single-Leg Dumbbell Cur & 2 & 12 & Slow & 0 & \\
\hline Triceps & $\begin{array}{l}\text { Supine Ball Dumbbell Triceps } \\
\text { Extensions }\end{array}$ & 2 & 12 & Slow & 0 & \\
\hline Legs & $\begin{array}{l}\text { Step-Up to Balance: } \\
\text { Sagittal Plane }\end{array}$ & 2 & 12 & Slow & 90 s. & \\
\hline
\end{tabular}

\begin{tabular}{|c|c|c|c|}
\hline \multicolumn{4}{|l|}{ COOL-DOWN } \\
\hline Exercise: & Sets & Duration & Coaching Tip \\
\hline Treadmill (optional) & 1 & 5-10 min & Brisk walk; gradually reduce speed \\
\hline SMR: Calves, IT-Band, Lats & 1 & $30 \mathrm{~s}$. & Hold each tender area for $30 \mathrm{sec}$ \\
\hline Static Stretch: Calves, Hip Flexors, Lats & 1 & $30 \mathrm{~s}$. & Hold each stretch for $30 \mathrm{sec}$ \\
\hline
\end{tabular}


5th.- 7th.Week : Strength Endurance, (1 RM \% 40-50)

Goals

Improve stabilization endurance and increase prime mover strength

Improve overall work capacity

Enhance joint stabilization

Increase lean body mass

Training Strategies

Moderate loads and repetitions (8-12)

Superset: one traditional strength exercise and one stabilization exercise per

body part in the resistance training portion of the program

GOAL: TOTAL BODY

PHASE: 2 STRENGTH ENDURANCE

WARM-UP

Exercise:

SMR: Calves, IT-Band, Lats

Active Stretch: Calves, Hip Flexors, Lats

Treadmill

\begin{tabular}{|l|c|c|c|c|c|}
\hline CORE / BALANCE / PLYOMETRIC \\
Exerclse: & Sets & Reps & Tempo & Rest & CoachIng Tip \\
\hline Ball Crunch & 2 & 10 & Medium & 0 & \\
\hline Reverse Crunch & 2 & 10 & Medium & 0 & \\
\hline Single-Leg Squat & 2 & 10 & Medium & 0 & \\
\hline Squat Jump & 2 & 10 & Medium & $60 \mathrm{~s}$. & \\
\hline
\end{tabular}

\begin{tabular}{|l|l|l|l|l|}
\hline SPEED, AGILITY, QUICKNESS \\
Exercise: & Sets & Reps & Rest & Coaching Tip \\
\hline Optional & & & & \\
\hline Optional & & & & \\
\hline
\end{tabular}

\begin{tabular}{|c|c|c|c|c|c|c|}
\hline \multicolumn{7}{|c|}{ RESISTANCE } \\
\hline Exerclse: & & Sets & Reps & Tempo & Rest & Coaching Tip \\
\hline Total Body & Optional & & & & & \\
\hline Chest & $\begin{array}{l}\text { Bench Press } \\
\text { Push-Up }\end{array}$ & 2 & $\begin{array}{l}12 \\
12\end{array}$ & $\begin{array}{l}\text { Medium } \\
\text { Slow }\end{array}$ & $\begin{array}{c}0 \\
60 \mathrm{~s} .\end{array}$ & Superset \\
\hline Back & $\begin{array}{l}\text { Seated Cable Row } \\
\text { Ball Dumbbell Row }\end{array}$ & 2 & $\begin{array}{l}12 \\
12\end{array}$ & $\begin{array}{l}\text { Medium } \\
\text { Slow }\end{array}$ & $\begin{array}{c}0 \\
60 \mathrm{~s} .\end{array}$ & Superset \\
\hline Shoulders & $\begin{array}{l}\text { Standing Dumbbell Should Press } \\
\text { Single-Leg Scaption }\end{array}$ & 2 & $\begin{array}{l}12 \\
12\end{array}$ & $\begin{array}{l}\text { Medium } \\
\text { Slow }\end{array}$ & $\begin{array}{c}0 \\
60 \mathrm{~s} .\end{array}$ & Superset \\
\hline Biceps & Optional & & & & & \\
\hline Triceps & Optional & & & & & \\
\hline Legs & $\begin{array}{l}\text { Leg Press } \\
\text { Step-Up to Balance }\end{array}$ & 2 & $\begin{array}{l}12 \\
12\end{array}$ & $\begin{array}{l}\text { Medium } \\
\text { Slow }\end{array}$ & $\begin{array}{c}0 \\
60 \mathrm{~s} .\end{array}$ & Superset \\
\hline
\end{tabular}

\section{COOL-DOWN}

\section{Exercise:}

Treadmill (optional)

SMR: Calves, IT-Band, Lats

Static Stretch: Calves, Hip Flexors, Lats

\begin{tabular}{|c|c|c|}
\hline Sets & Duration \\
\hline 1 & $30 \mathrm{~s}$. \\
\hline 1 & $10 \mathrm{reps}$ \\
\hline
\end{tabular}

Coaching Típ

Hold each tender area for $30 \mathrm{sec}$ Hold each stretch for 1-2 sec

Brilsk walk to slow jog

Coaching Tips: Resistance program can be split into 2, 3, or 4-day workout routine. Ex. 3-day routine:

Day 1 (chest/back) Day 2 (legs) Day 3 (shoulders/biceps/triceps) 
8th.-11th.Week : Hypertrophy (1 RM \% 65-85)

Goal

Achieve optimal levels of muscular hypertrophy (increase muscle size)

Training Strategies

High volume, moderate to high loads, moderate or low repetitions (6-12)

GOAL: TOTAL BODY

PHASE: 3 HYPERTROPHY

\begin{tabular}{|c|c|c|c|}
\hline Exercise: & Sets & Duration & Coaching Tip \\
\hline SMR: Calves, IT-Band, Lats & 1 & $30 \mathrm{~s}$. & Hold each tender area for $30 \mathrm{sec}$ \\
\hline Active Stretch: Calves, Hip Flexors, Lats & 1 & 10 reps & Hold each stretch for $1-2 \mathrm{sec}$ \\
\hline Treadmill & 1 & $5-10 \mathrm{~min}$ & Brisk walk to slow jog \\
\hline
\end{tabular}

\begin{tabular}{|l|c|c|c|c|c|}
\hline CORE / BALANCE / PLYOMETRIC \\
\hline Exercise: & Sets & Reps & Tempo & Rest & Coaching Tip \\
\hline Ball Crunch & 2 & 12 & Medium & 0 & \\
\hline Reverse Crunch & 2 & 12 & Medium & 0 & \\
\hline Single-Leg Romanian Deadlift & 2 & 12 & Medium & 0 & \\
\hline Squat Jump & 2 & 10 & Medium & 60 s. & \\
\hline
\end{tabular}

\begin{tabular}{|l|l|l|l|l|}
\hline SPEED, AGILITY, QUICKNESS \\
\hline Exercise: & Sets & Reps & Rest & Coaching Tip \\
\hline Optional & & & & \\
\hline Optional & & & & \\
\hline
\end{tabular}

\begin{tabular}{|c|c|c|c|c|c|c|}
\hline \multicolumn{7}{|c|}{ RESISTANCE } \\
\hline Exercise: & & Sets & Reps & Tempo & Rest & Coaching Tip \\
\hline Total Body & Optional & & & & & \\
\hline Chest & Bench Press & 3 & 10 & Medium & $60 \mathrm{~s}$. & \\
\hline Back & Lat Pulldown & 3 & 10 & Medium & $60 \mathrm{~s}$. & \\
\hline Shoulders & Shoulder Press Machine & 3 & 10 & Medium & $60 \mathrm{~s}$. & \\
\hline Biceps & Standing 2-arm Dumbbell Curl & 3 & 10 & Medium & $60 \mathrm{~s}$. & \\
\hline Triceps & Cable Pressdown & 3 & 10 & Medium & $60 \mathrm{~s}$. & \\
\hline Legs & Leg Press & 3 & 10 & Medium & $60 \mathrm{~s}$. & \\
\hline
\end{tabular}

\begin{tabular}{|l|c|c|l|}
\hline COOL-DOWN & Sets & Duration & \multicolumn{1}{|c|}{ Coaching Tip } \\
\hline Exercise: & 1 & $5-10$ min & Brisk walk \\
\hline Treadmill (optional) & 1 & $30 \mathrm{~s}$. & Hold each tender area for $30 \mathrm{sec}$ \\
\hline SMR: Calves, IT-Band, Lats & 1 & $30 \mathrm{~s}$. & Hold each stretch for $30 \mathrm{sec}$ \\
\hline Static Stretch: Calves, Hip Flexors, Lats & &
\end{tabular}

Coaching Tips: Resistance program can be split into 2, 3, or 4-day workout routine. Ex. 3-day routine:

Day 1 (chest/back) Day 2 (legs) Day 3 (shoulders/biceps/triceps) 
12th.-15th. : Max Strength, (1 RM \% 90-100)

Goals

Increase motor unit recruitment

Increase frequency of motor unit recruitment

Improve peak force

Training Strategies

High loads, low repetitions (1-5), longer rest periods

GOAL: TOTAL BODY

PHASE: 4 MAX STRENGTH

\begin{tabular}{|c|c|c|c|}
\hline WARM-UP & & & \\
\hline Exercise: & Sets & Duration & Coaching Tip \\
\hline SMR: Calves, IT Band, Adductors & 1 & $30 \mathrm{~s}$. & Hold each tender area for $30 \mathrm{sec}$ \\
\hline Active Stretch: Calves, Hip Flexors, Lats & 1 & 10 reps & Hold each stretch for $1-2 \mathrm{seq}$ \\
\hline Treadmill & 1 & $5-10 \mathrm{~min}$ & Brisk walk to slow jog \\
\hline
\end{tabular}

\section{CORE / BALANCE / PLYOMETRIC}

\begin{tabular}{|l|c|c|c|c|c|}
\hline Exercise: & Sets & Reps & Tempo & Rest & Coaching Tip \\
\hline Cable Rotations & 2 & 8 & Medium & 0 & \\
\hline Back Extension & 2 & 8 & Medium & 0 & \\
\hline Step-Up to Balance & 2 & 8 & Medium & $60 \mathrm{~s}$. & \\
\hline
\end{tabular}

\begin{tabular}{|l|c|c|c|c|}
\hline SPEED, AGILITY, QUICKNESS \\
\hline Exercise: & Sets & Reps & Rest & Coaching Tip \\
\hline Optional & & & & \\
\hline Optional & & & & \\
\hline
\end{tabular}

\begin{tabular}{|c|c|c|c|c|c|c|}
\hline \multicolumn{7}{|c|}{ RESISTANCE } \\
\hline Exercise: & & Sets & Reps & Tempo & Rest & Coaching Tip \\
\hline Total Body & Barbell Clean & 4 & 5 & Explosive & $3 \mathrm{~min}$ & \\
\hline Chest & Bench Press & 4 & 5 & Explosive & $3 \mathrm{~min}$ & \\
\hline Back & Lat Pulldown & 4 & 5 & Explosive & $3 \mathrm{~min}$ & \\
\hline Shoulders & Seated Dumbbell Shoulder Press & 4 & 5 & Explosive & $3 \mathrm{~min}$ & \\
\hline Biceps & Optional & & & & & \\
\hline Triceps & Optional & & & & & \\
\hline Legs & Barbell Squat & 4 & 5 & Explosive & $3 \mathrm{~min}$ & \\
\hline
\end{tabular}

\section{COOL-DOWN}

Exercise:

SMR: Calves, IT-Band, Lats

Static Stretch: Calves, Hip Flexors, Lats

\begin{tabular}{|c|c|c|} 
& Sets & Duration \\
& 1 & $5-10 \mathrm{~min}$ \\
\hline & 1 & $30 \mathrm{~s}$. \\
\hline
\end{tabular}

\begin{tabular}{|l|}
\hline \multicolumn{1}{|c|}{ Coaching Tip } \\
\hline Brisk walk \\
\hline Hold each tender area for 30 sec \\
\hline Hold each stretch for 30 sec \\
\hline
\end{tabular}

Coaching Tips: Resistance program can be split into 2, 3, or 4-day workout routine. Ex. 3-day routine:

Day 1 (chest/back) Day 2 (legs) Day 3 (shoulders/biceps/triceps) 
16th.18th: Power (1 RM \% 40-50)

Goals

Enhance neuromuscular efficiency

Enhance prime mover strength

Increase rate of force production

Training Strategies

Superset: one strength and one power exercise per body part in the resistance

training portion of the program

Perform all power exercises as fast as can be controlled (26)

GOAL: TOTAL BODY

PHASE: 5 POWER

\begin{tabular}{|l|c|c|c|}
\hline WARM-UP & Sets & Duration & Coaching Tip \\
\hline Exercise: & 1 & $30 \mathrm{~s}$. & Hold each tender area for 30 sec \\
\hline SMR: Calves, IT-Band, Lats & 1 & 10 reps & \\
\hline $\begin{array}{l}\text { Dynamic Stretch: Tube Walking, Multiplanar } \\
\text { Lunges, Med Ball Lift and Chop }\end{array}$ & 1 & \\
\hline
\end{tabular}

\begin{tabular}{|l|c|c|c|c|c|}
\hline CORE / BALANCE / PLYOMETRIC \\
Exercise: & Sets & Reps & Tempo & Rest & \\
\hline Med Ball Rotation Chest Pass & 2 & 8 & Fast & 0 & \\
\hline Single-Leg Hop with Stabilization & 2 & 8 & Medium & $60 \mathrm{~s}$. & \\
\hline
\end{tabular}

\begin{tabular}{|l|l|l|l|l|}
\hline SPEED, AGILITY, QUICKNESS \\
Exercise: & Sets & Reps & Rest & Coaching Tip \\
\hline Optional & & & & \\
\hline Optional & & & & \\
\hline
\end{tabular}

\begin{tabular}{|c|c|c|c|c|c|c|}
\hline \multicolumn{7}{|c|}{ RESISTANCE } \\
\hline Exercise: & & Sets & Reps & Tempo & Rest & Coaching Tip \\
\hline Total Body & Optional & & & & & \\
\hline Chest & $\begin{array}{l}\text { Bench Press } \\
\text { Med Ball Chest Pass }\end{array}$ & 4 & $\begin{array}{c}5 \\
10\end{array}$ & Explosive & $\begin{array}{c}0 \\
2 \min \end{array}$ & Superset \\
\hline Back & $\begin{array}{l}\text { Lat Pulldown } \\
\text { Woodchop Throw }\end{array}$ & 4 & $\begin{array}{c}5 \\
10\end{array}$ & Explosive & $\begin{array}{c}0 \\
2 \mathrm{~min}\end{array}$ & Superset \\
\hline Shoulders & $\begin{array}{l}\text { Standing Dumbbell Should Press } \\
\text { Med Ball Scoop Toss }\end{array}$ & 4 & $\begin{array}{c}5 \\
10\end{array}$ & Explosive & $\begin{array}{c}0 \\
2 \min \end{array}$ & Superset \\
\hline Biceps & Optional & & & & & \\
\hline Triceps & Optional & & & & & \\
\hline Legs & $\begin{array}{l}\text { Barbell Squat } \\
\text { Squat Jump }\end{array}$ & 4 & $\begin{array}{c}5 \\
10\end{array}$ & Explosive & $\begin{array}{c}0 \\
2 \mathrm{~min}\end{array}$ & Superset \\
\hline
\end{tabular}

\begin{tabular}{|c|c|c|c|}
\hline COOL-DOWN & & & \\
\hline Exercise: & Sets & Duration & Coaching Tip \\
\hline Treadmill (optional) & 1 & $5-10 \mathrm{~min}$ & Brisk walk \\
\hline SMR: Calves, IT-Band, Lats & 1 & $30 \mathrm{~s}$. & Hold each tender area for $30 \mathrm{sec}$ \\
\hline Static Stretch: Calves, Hip Flexors, Lats & 1 & $30 \mathrm{~s}$. & Hold each stretch for $30 \mathrm{sec}$ \\
\hline
\end{tabular}

PT Group: This group consists of the individuals continuing the Koza Wos The Club fitness center in Esenyurt, that takes place in the European side of Istanbul in Turkey for at least 1 year and making exercise for at least 2 days a week. PT group was subject to a training program which was determined and specially applied by the trainer and of which the exercise periods did not exceed one hour. 


\section{Measurements}

\section{Measuring Resting HR}

Your heart rate can be taken at any spot on the body at which an artery is close to the surface and a pulse can be felt. The most common places to measure heart rate using the palpation method is at the wrist (radial artery) and the neck (carotid artery).

Other places sometimes used are the elbow (brachial artery) and the groin (femoral artery). You should always use your fingers to take a pulse, not your thumb, particularly when recording someone else's pulse, as you can sometimes feel your own pulse through your thumb. (32)

\section{Manual Method}

Radial Pulse (wrist) - place your index and middle fingers together on the opposite wrist, about $1 / 2$ inch on the inside of the joint, in line with the index finger. Once you find a pulse, count the number of beats you feel within a one minute period.

Carotid Pulse (neck) - to measure your heart rate at the neck, place your first two fingers on either side of the neck until you can feel the beats. Be careful not too press to hard, then count the number of beats for a minute.

You can estimate the per minute rate by counting over 10 seconds and multiplying this figure by six, or count over 15 seconds and multiply by four, or over 30 seconds and doubling the result. There are obvious potential errors by using this shorthand method. The longer you can measure for the more accurate your result. If you have a heart rate monitor, this will usually give you an accurate reading.

The measurement of resting heart rate or pulse rate (the number of heart beats per minute) should be taken after a few minutes upon waking whilst still lying in bed. Give your body some time to adjust to the change from sleeping before taking your pulse (2-5 minutes). If you are not able to take a measurement first thing in the morning, make sure you lie down for at least 10 minutes before taking a measurement. Taking a radial or carotid pulse measurement (at the wrist or neck) is usually the easiest method.

\section{Systolic and Diastolic Blood Pressure}

Omron m2 HEM-7121 memory digital arm blood pressure monitor was used to measure systolic and diastolic blood pressure.

\section{Body Mass Index (BMI)}

In the study; for height measurements, standing upright, Holtain Portable Stadiometer was used to fit the head frankfort plan (nasofrontal angle; area of the forehead and nose).

For body weight, body fat and body mass measurement; Sensitivity $\pm 0,1 \mathrm{~kg}$. The electronic Tanita BC 418 Segmentel body composition was used.

BMI is the ratio of body weight to neck square.

$\operatorname{BMI}\left(\mathrm{kg} / \mathrm{m}^{\wedge} 2\right)=\mathrm{VA}(\mathrm{kg}) /$ Height $\wedge 2(\mathrm{~m})$

Note: The most important thing to know is that the BMI is an index in which the obesity is roughly calculated, and it should be remembered that it should be used to estimate body fat. (30)

Kaup BMI Grouping (Kaup Index) (30)

\section{Hand Grip Strength}

\begin{tabular}{ccc}
\hline BMI & STATUS & FOR KIDS \\
\hline Less than 20 & Weak & Less than 14 \\
$\mathbf{2 0}$ to 25 & Healthy & $14.5-15$ \\
$\mathbf{2 5}$ to 30 & Light Fat & $16-16$ \\
30 and above & Fat & Over 16 \\
\hline
\end{tabular}

The purpose of this test is to measure the maximum isometric strength of the hand and forearm muscles. Handgrip strength is important for any sport in which the hands are used for catching, throwing or lifting. Also, as a general rule people with strong hands tend to be strong elsewhere, so this test is often used as a general test of strength.

Equipment required: Electronic hand dynamometer

Procedure: The subject holds the dynamometer in the hand to be tested, with the arm at right angles and the elbow by the side of the body. The handle of the dynamometer is adjusted if required - the base should rest on first metacarpal (heel of palm), while the handle should rest on middle of four fingers. When ready the subject squeezes the 
dynamometer with maximum isometric effort, which is maintained for about 5 seconds. No other body movement is allowed. The subject should be strongly encouraged to give a maximum effort. (28)

\section{Push-Up Test:}

Purpose: Push-ups are used to assess the strength and endurance of the upper body muscles in the shoulders, chest, and back of the upper arms (the triceps).

Equipment required: floor mat or other flat surface, 4 inch foam cube.

Procedure: The aim of this test is to perform as many push-ups in you can. The starting position is with your arms straight with the elbows locked, body in a straight line, hands placed slightly wider than shoulder-width apart with fingers pointing forward, and both feet on the floor. A foam block is placed under the chest (located at the costal arch and above the zyphoid bone). The subject lowers their body until they slightly compress the foam cube, and arms are at least parallel to the floor, then pushes up again. The back must be kept straight, and in each extension up, the elbows should lock. Resting is allowed, though only in the up (starting) position.

Scoring: The maximum number of correctly performed push ups is recorded. There are some individuals who can do a lot of consecutive pushups, so it may be appropriate to have a maximum that when it is reached the participant stops the test. See push up records to see what people are capable of doing. (32)

\section{Wall Sit Test (Sqaut Position)}

purpose: to measure the strength endurance of the lower body, particularly the quadriceps muscle group.

Equipment required: smooth wall and a stopwatch

a $90^{\circ}$ angle. The timing starts when one foot is lifted off the ground and is stopped when the subject cannot maintain the position and the foot is returned to the ground. After a period of rest, the other leg is tested.

Scoring: the total time in seconds that the position was held for each leg is recorded. The table below gives a general guideline to expected scores for a single leg for adults, based on my personal experiences. Comparing the scores for each leg may indicate muscle weakness on one side. (32-33)

\section{PFT Sit -Up Test (Crunches)}

Purpose: This test measures the endurance of the abdominal and hip-flexor muscles.

Equipment required: flat ground, stopwatch

Procedure: The aim of this test is to perform as many sit-ups as you can in two minutes. The starting position is lying on your back with your knees bent and feet flat on the floor. The arms are folded across and the chest, and must maintain no gap between the forearms and the chest at all times. A second person is permitted to hold the lower legs or ankles. On the command 'go,' start the crunch by raising your upper body forward until the elbows or forearms touch the thighs, and then lower the torso until the shoulder blades touch the ground. This is one complete sit up. (33)

\section{Plank Test (Core Stabilization)}

The plank test is a simple fitness test of core muscle strength, and can also be used as a fitness exercise for improving core strength.

Purpose: The plank test measures the control and endurance of the back/core stabilizing muscles.

Equipment required: flat and clean surface, stopwatch, recording sheets, pen.

Procedure: The aim of this test is to hold an elevated position for as long as possible. Start with the upper body supported off the ground by the elbows and forearms, and the legs straight with the weight taken by the toes. The hip is lifted off the floor creating a straight line from head to toe. As soon as the subject is in the correct position, the stopwatch is started. The test is over when the subject is unable to hold the back straight and the hip is lowered.

Scoring: The score is the total time completed. (33)

\section{Bruce Protocol Stress Test (Max Vo ${ }^{2}$ )}

The Bruce Test is commonly used treadmill exercise stress test. It was developed as a clinical test to evaluate patients with suspected coronary heart disease, though it can also be used to estimate cardiovascular fitness. See also a general description of Exercise Stress Tests. As this stress test is a maximal test performed commonly on people with heart problems, the test should be performed under the supervision of appropriately trained medical staff.

Aim: to evaluate cardiac function and fitness.

Equipment required: treadmill, stopwatch 
Procedure: Exercise is performed on a treadmill. The treadmill is started at $2.74 \mathrm{~km} / \mathrm{hr}(1.7 \mathrm{mph})$ and at a gradient (or incline) of $10 \%$. At three minute intervals the incline of the treadmill increases by $2 \%$, and the speed increases as shown in the table below. The test should be stopped when the subject cannot continue due to fatigue or pain, or due to many other medical indications. (33)

Results: The test score is the time taken on the test, in minutes. This can also be converted to an estimated VO2max score using the calculator below and the following formulas, where the value " $\mathrm{T}$ " is the total time completed (expressed in minutes and fractions of a minute e.g. 9 minutes 15 seconds $=9.25$ minutes). As with many exercise test equations, there have been many regression equations developed that may give varying results. If possible, use the one derived from a similar population and which best suits your needs.

$\operatorname{VO} 2 \max (\mathrm{ml} / \mathrm{kg} / \mathrm{min})=14.76-(1.379 \times \mathrm{T})+\left(0.451 \times \mathrm{T}^{2}\right)-\left(0.012 \times \mathrm{T}^{3}\right)($ this formula is the one used for the calculator below)

Women: VO2max $(\mathrm{ml} / \mathrm{kg} / \mathrm{min})=2.94 \times \mathrm{T}+3.74$

Women: $\operatorname{VO} 2 \max (\mathrm{ml} / \mathrm{kg} / \mathrm{min})=4.38 \times \mathrm{T}-3.9$

Men: VO2max $(\mathrm{ml} / \mathrm{kg} / \mathrm{min})=2.94 \times \mathrm{T}+7.65$

Young Men: VO2max $(\mathrm{ml} / \mathrm{kg} / \mathrm{min})=3.62 \times \mathrm{T}+3.91(34)$

\section{Sit and Reach}

Equipment required: sit and reach box (or alternatively a ruler can be used, and a step or box).

Procedure: This test involves sitting on the floor with legs stretched out straight ahead. Shoes should be removed. The soles of the feet are placed flat against the box. Both knees should be locked and pressed flat to the floor - the tester may assist by holding them down. With the palms facing downwards, and the hands on top of each other or side by side, the subject reaches forward along the measuring line as far as possible. Ensure that the hands remain at the same level, not one reaching further forward than the other. After some practice reaches, the subject reaches out and holds that position for at one-two seconds while the distance is recorded. Make sure there are no jerky movements.

Scoring: The score is recorded to the nearest centimeter or half inch as the distance reached by the hand. Some test versions use the level of the feet as the zero mark, while others have the zero mark 9 inches before the feet.

The sit and reach test is a common measure of flexibility, and specifically measures the flexibility of the lower back and hamstring muscles. This test is important as because tightness in this area is implicated in lumbar lordosis, forward pelvic tilt and lower back pain. This test was first described by Wells and Dillon (1952) and is now widely used as a general test of flexibility. (28-29)

Statistical Analysis: After the data obtained is entered in computer environment; the arithmetic means (X), standard deviations (ss) of the research groups are taken and the Paired Samples t-test is applied for the differences between the pre-test and posttest. Significance level is examined at $\mathrm{p}<0.05$ level.

\section{Findings}

Table 1. OPT-EMG group's descriptive statistics table

\begin{tabular}{cccccc}
\hline Variable & n & Minimum & Maximum & Mean & Std. \\
\hline Age & 30 & 18 & 51 & 37.75 & 11.965 \\
Height & 30 & 164.60 & 189.70 & 175.99 & 7.024 \\
Body Weight & 30 & 65.80 & 114.90 & 84.86 & 10.693
\end{tabular}

When Table 1 is examined, it is determined that the age average of OPT-EMS group is $37,75 \pm 11,965$ years, height average is $175,99 \pm 7,024 \mathrm{~cm}$ and body weight average is $84,86 \pm 10,693 \mathrm{~kg}$.

Table 2. PT group's descriptive statistics table

\begin{tabular}{|c|c|c|c|c|c|}
\hline Variable & $\mathbf{n}$ & Minimum & Maximum & Mean & Std. \\
\hline Age & 30 & 17 & 48 & 35.24 & 10.957 \\
\hline Height & 30 & 164.50 & 189.70 & 173.35 & 7.661 \\
\hline Body Weigh & 30 & 55.40 & 93.80 & 79.56 & 11.308 \\
\hline
\end{tabular}

When Table 2 is examined, it is determined that the age average of PT group is $35,24 \pm 10,957$ years, height average is $173,35 \pm 7,661 \mathrm{~cm}$ and body weight average is $79,56 \pm 11,308 \mathrm{~kg}$. 
Table 3. OPT-EMS group pretest-posttest comparison

\begin{tabular}{cccccc}
\hline Variables & $\mathbf{n}$ & $\begin{array}{c}\text { Pre-Test } \\
\text { Mean } \pm \text { Std. }\end{array}$ & $\begin{array}{c}\text { Post-test } \\
\text { Mean } \pm \text { Std }\end{array}$ & $\mathbf{t}$ & $\mathbf{p}$ \\
\hline Systolic & 30 & 130.8095 & 125.8571 & 1.528 &, 318 \\
Diastolic & 30 & 79.6667 & 76.8571 & 1.668 &, 681 \\
Rest HR & 30 & 73.0952 & 68.6190 & 2.140 &, 494 \\
BMI & 30 & 27.4097 & 27.2513 &, 327 &, 890 \\
Body Fat & 30 & 21.6229 & 19.2576 & 1.262 &, 532 \\
Hand Grip Right & 30 & 43.1667 & 44.5381 &,- 925 &, 749 \\
Hand Grip Left & 30 & 38.5429 & 42.3571 & -2.938 &, 375 \\
Push-Up Test & 30 & 21.0952 & 23.4286 & -1.895 &, $\mathbf{0 0 0}$ \\
Squat Test & 30 & 55.8857 & 65.8095 & -1.187 & $\mathbf{, 0 0 8}$ \\
Crunch test & 30 & 23.2381 & 25.0476 & -1.124 & $\mathbf{, 0 1 4}$ \\
Plank Test & 30 & 85.0286 & 110.7048 & -2.905 & $\mathbf{, 0 0 3}$ \\
Max Vo ${ }^{2}$ & 30 & 34.0143 & 39.3190 & -2.009 & $\mathbf{, 0 0 1}$ \\
Seat and Reach & 30 & 21.5476 & 23.0000 &,- 775 &, 113 \\
Body Mass & 30 & 1.0489 & 1.0545 & -1.271 &, 543 \\
\hline
\end{tabular}

$\mathrm{p}<0,05^{*}$

When Table 3 is examined, statistically significant differences are observed in the push-up, squat, crunch, plank and Max Vo2 performance measurements of the participants in 20-week OPT-EMS group ( $\mathrm{p}<0.05$ ). It is observed that there is no statistically significant difference in the systolic, diastolic, rest hr, BMI, Right-left hand grip strength, Body fat, seat and reach and body mass performance measurements.

Table 4. PT group pretest-posttest comparison

\begin{tabular}{cccccc}
\hline Variables & $\mathbf{n}$ & $\begin{array}{c}\text { Pre-Test } \\
\text { Mean } \pm \text { Std. }\end{array}$ & $\begin{array}{c}\text { Post-test } \\
\text { Mean } \pm \text { Std. }\end{array}$ & $\mathbf{t}$ & $\mathbf{p}$ \\
\hline Systolic & 30 & 127.0714 & 121.0000 & 1.038 &, 142 \\
Diastolic & 30 & 79.2143 & 77.8571 &, 421 &, 111 \\
Rest HR & 30 & 71.0714 & 68.5714 &, 705 &, 055 \\
BMI & 30 & 26.7709 & 27.0239 &,- 141 &, 747 \\
Body Fat & 30 & 24.4207 & 22.4793 &, 641 &, 222 \\
Hand Grip Right & 30 & 41.4786 & 42.4143 &,- 327 &, 366 \\
Hand Grip Left & 30 & 39.5214 & 42.3786 &,- 918 & $\mathbf{, 0 0 8}$ \\
Push-Up Test & 30 & 16.3571 & 25.4286 & -4.992 &, 073 \\
Squat Test & 30 & 42.0571 & 75.1000 & -3.141 &, 249 \\
Crunch test & 30 & 20.5714 & 25.4286 & -2.842 &, 274 \\
Plank Test & 30 & 59.5000 & 89.0714 & -3.657 &, $\mathbf{0 0 9}$ \\
Max Vo ${ }^{2}$ & 30 & 26.2000 & 37.7071 & -4.245 &, 058 \\
Seat and Reach & 30 & 15.7143 & 21.6071 & -1.702 &, 447 \\
Body Mass & 30 & 1.0422 & 1.0467 &,- 625 &, 218 \\
\hline & & & & &
\end{tabular}

$\mathrm{p}<0,05^{*}$

When Table 4 is examined, it is determined that there is no statistically significant difference in the systolic, diastolic, rest hr, BMI, Right hand grip strength, push-up, squat, crunch, max $\mathrm{vo}^{2}$, seat and reach and body mass performance measurements.

\section{Discussion and Conclusion}

Given the study results conducted for determining whether or not there is a development in physical performance of exercising individuals with OPT-EMS and PT exercise models within 20-weeks exercise program, statistically significant difference has been found out in push-up, squat, crunch, plank and Max Vo2 performance measurements of 20-weeks OPT-EMS group participants and left-hand grip and plant test performance measurements of 20-weeks PT group participants $(\mathrm{p}<0.05)$.

As a result of the literature review, no similar study on OPT-EMS and PT training has been encountered. However, in the study conducted by Biylklı et al. (2018) on 11 male national football players with visual handicap where OPT model is used, they have applied force and condition programs according to OPT model. As a result of the study, significant differences have been found out hand grip and $\mathrm{Max} \mathrm{Vo}^{2}$ performances.

Given the literature, the studies have been conducted on the role of EMS system during muscular force development, effects on performance or recovering disabilities in exercise and sports area. For example, Kaçoğlu and Kale (2014) has examined tolerance development against electrical muscular stimuli during a period of 5 weeks and have observed that 
tolerance has exhibited a rapid increase at the beginning as a result of result of this process, this rapid increase is followed by a short halt and then, an increase has been in question again and following this increase, a slight decline has been seen in the recent periods of the training. Baskan (2009) compared the effects o electrical stimulation and isometric exercise on isokinetic strength of healthy quadriceps femoris muscle and as a result, they have revealed that force training and electrical stimulation and maximal voluntary isometric contraction applied on healthy quadriceps femoris muscle has led to an increase on the muscular force, endurance and isokinetic parameters. The results as a result of the study conducted on performance are remarkable. Brocherie, Babault, Cometti, Maffiuletti and Chatard (2004) examined EMS effects of ice hockey players on their physical performances and conducted a study on 70 ice hockey players and an EMS training program of 3 weeks was applied. As a result of the study, they recorded an increase in both the eccentric and concentric dimension in isokinetic torque and vertical jump and they exhibited performance improvement in $10 \mathrm{~m}$ sliding.

The content of PT training varies according to trainer and individual. This is a system where all kinds of exercises can be added to the program. Core training, high-intensity training (HIIT) and plyometric studies can be incorporated into the training program. It can be said that PT training with a wide range of training styles can contribute to physical performance development with its versatility feature. It has been started to be preferred in recent times since different training types can be applied concomitantly. It has been determined that core training so applied (Boyac1 and Afyon, 2017; Afyon and Boyac1, 2013; Saeterbakken et al., 2011; Jim et al., 2013; Thomas et al., 2009; Boyac1 et al, 2018; Boyacı and Tutar;, 2018; Basset and Leach, 2011; Willardson, 2007; Afyon and Boyac1, 2016) HIIT (Tabata et al., 1996; Tong et al., 2011; Esfarjani and Laursen, 2007; Jacops et al., 2013; Talanian et al., 2007 ) and plyometric training improve physical performance. (Michalopoulou et al., 2013; Meyer et al., 2013; Lappe et al., 2015; Chelly et al., 2014; Rubley et al., 2011).

As a result, it can said that keeping on with the training OPT model that is an innovative approach and having five different training phase and EMG for a particular period in addition to this model can make a contribution to physical performance. In addition to this, if PT training content is prepared appropriately for a person, it is considered that it can make a contribution to physical performance. For this reason, the needs of a person should be accurately identified and it should be worked out in a purposed oriented manner. It can be recommended that OPT model training is applied for elite athletes and it can shed light on new studies. Also the PT service gives support for the continuity of exercise motivation. Başoğlu (2018) has find out that as the frequency of exercise in terms of days per week and hours per day increases, so the level of exercise addiction increases either. Moreover, the exercise addiction level of the individuals taking the personal exercise training is higher than the others.

\section{References}

Afyon, Y. A., \& Boyacı, A. (2013). Investıgatıon Of The Effects By Compositely Edıted Core-Plyometric Exercises in Sedentary Man On Some Physical and Motoric Parameters. International Journal of Academic Research, 5(3).

Afyon, Y. A., \& Boyac1, A. (2016). The effect of 8 week core training on the development of some motoric traits in 18 year old football players. Journal of Human Sciences, 13(3), 4595-4603. https://doi.org/10.14687/jhs.v13i3.3924

Afyon, Y. A., \& Boyac1, A. (2016). The effects of 8-week core training on the development of some motoric features among 18 year-old footballers. Journal of Human Sciences, 13(3), 4595-4603.

https://doi.org/10.14687/jhs.v13i3.3924

Baskan, E. (2009). Comparison of the Effects of Electrical Stimulation and Isometric Exercise on the Isokinetic strength of Healthy Quadriceps Femoris Muscle. Pamukkale University, Institute of Health Sciences. PhD Thesis.

Başoğlu, U. (2018). Exercise Addiction: A Comparison Between the Individuals Who Exercise for Physical Recreation and Who Receive Personal Exercise Training. Journal of Education and Training Studies, 6(12), https://doi.org/10.11114/jets.v6i12.3604

Boyac1, A., \& Afyon, Y. A. (2017). The Effect of the Core Training to Physical Performances in Children. Journal of Education and Practice, 8(33), 81-88.

Boyac1, A., \& Tutar, M. (2018). The Effecet of the Quad-Core Training on Core Muscle Strength and Endurance. International Journal of Sports Science, 8(2), 50-54.

Brocherie, F., Babault, N., Cometti, G., Maffiuletti, N., \& Chatard, J. C. (2004). Elecktrostimulatıon Training Effeckts On The Physical Performance Of Ice Hockey Players. Medicine \& Science in Sports \& Exercise, 455-460.

Chelly, M. S., Hermassi, S., Aouadi, R., \& Shephard, R. J. (2014). Effects of 8-Week In-Season Plyometric Training on Upper And Lower Limb Performance of Elite Adolescent Handball Players. The Journal of Strength \& Conditioning Research, 28(5), 1401-1410. https://doi.org/10.1519/JSC.0000000000000279 
Clark, A. M., Lucett, C. S., McGill, E., Montel, I., \& Sutton, B. (2017). SixthEdition NASM (National Academy of Sports Medicine) - Essentials of Personal Fitness Training, Jones \& Bartlett Learning

Clark, M. A., Lucett, S. C., McGill, E., Montel, I., \& Sutton, B. National Academy of Sports Medicine, an Ascend Learning Company - Chapter 1- The Scientific Rationale for Integrated Training 8-15

Esfarjan1, F., \& Laursen, P. B. (2007): Manipulating high-intensity interval training: Effects on 'VO2 max, the lactate threshold and3000m running performance in moderately trained males. Journal of Science and Medicine in Sport, 10, 27-35. https://doi.org/10.1016/j.jsams.2006.05.014

Günay, M., Tamer, K., \& Cicioğlu, İ. (2013). Sports Physiology and Performance Measurement, 3rd ed., Ankara, Gazi Kitabevi Tra. Lim. Com.

Holcomb, W. R. (2006). Effect Of Training With Neuromuscular Electrical Stimulation On Elbow Flexion Strength. Journal of Sports Science and Medicine, 5, 276-281.

Jacobs, R. A., Fluck, D., Bonne, T. C., Burgi, S., Christensen, P. M., Toigo, M., \& Lundby, C. (2013). Improvements in exercise performance with high intensity interval training coincide with an increase in skeletal muscle mitochondrial content and function. J. Appl. Physiol., 8, 785-793. https://doi.org/10.1152/japplphysiol.00445.2013

Jim, F. S., Jeff, C. M., John, R. B., \& Jacob, L. T. (2012). Effect Of Core Strength And Endurance Training On Performance in College Students: Randomized Pilot Study. Department of Exercise, Health, and Sport Sciences, $17,278-290$.

Kaçoğlu, C., \& Kale, M. (2014). Developing Tolerance Against Electrical Muscle Stimuli.

Kaçoğlu, C., \& Kale, M. (2015). Electrical Current Parameters and Methodology Related to Electromyo stimulation. CBU Journal of Physical Education and Sport Sciences, 10(2), 34-47

Kamar, A. (2008). Talent, Skill and Performance Tests in Sport, 2nd Ed., Ankara, Nobel Yayın Dağıtım Tra. Lim. Com.

Kaminksy, L. A. (2014). ACSM's Health-Related Physical Fitness Assessment Manual - 4th.ed.-2014

Lappe, J. M, Watson, P., Gilsanz, V., Hangartner, T., Kalkwarf, H. J., Oberfield, S., ... \& Zemel, B. (2015). The Longitudinal Effects of Physical Activity and Dietary Calcium on Bone Mass Accrual Across Stages of Pubertal Development. Journal of Bone and Mineral Research, 30(1), 156-164. https://doi.org/10.1002/jbmr.2319

Mackenzie, B. (2005). 101 Performance Evaluation Tests, London, Elektric Word Plc. www.brianmac.co.uk/eval.htm,17/09/2018

Meyer, U., Ernst, D., Zahner, L., Schindler, C., Puder, J. J., Kraenzlin, M., Rizzoli, R., \& Kriemler, S. (2013). 3-Year Follow-Up Results of Bone Mineral Content And Density After A School Based Physical Activity Randomized Intervention Trial. Bone, 55, 122. https://doi.org/10.1016/j.bone.2013.03.005

Michalopoulou, M., Kambas, A., Leontsini, D., Chatzinikolaou, A., Draganidis, D., Avloniti, A., ... \& Fatouros, I. G. (2013). Physical Activity Is Associated With Bone Geometry Of Premenarcheal Girls In A Dose-Dependent Manner. Metabolism Clinical and Experimental. 62, 1811-1818. https://doi.org/10.1016/j.metabol.2013.08.006

Rubley, M. D., Haase, A. C., Holcomb, W. R., Girouard, T. J., \& Tandy, R. D. (2011). The Effect of Plyometric Training on Power and Kicking Distance in Female Adolescent Soccer Players. The Journal of Strength \& Conditioning Research. 25(1), 129-134. https://doi.org/10.1519/JSC.0b013e3181b94a3d

Saeterbakken, H. A., Van, T. R., \& Seiler, S. (2011). Effect of Core Stability Training on Throwing Velocity in Female Handball Players, Journal of Strength \& Conditioning Research, 25(3), 712-718. https://doi.org/10.1519/JSC.0b013e3181cc227e

Tabata, I., Nischimura, K., Kouzaki, M., Hirai, Y., Ogita, F., Miyachi, M. \& Yamamoto, K. (1996). Effects of moderate-intensity endurance and high-intensity intermittent training on anaerobic capacity and VO2 max. Medicine \& Science in Sports \& Exercise, 28(10), 1327-1330. https://doi.org/10.1097/00005768-199610000-00018

Talanian, J. L., Stuart, D. R. G., George, J. F., Bonen, H. A., \& Spriet, L. L. (2007). Two weeks of high-intensity aerobic interval training increases the capacity for fat oxidation during exercise in women. J. Appl. Physiol., 102, 1439-1447. https://doi.org/10.1152/japplphysiol.01098.2006

Thomas, W. N., \& William, L. L. (2009). The Relationship Between Core Strength and Performans İn Division 1. Female Soccer Player, Journal of Exercises Physiology, 12(2), USA.

Tonk, T. K., Chung, P. K., Leung, R. W., Nie, J., Lin, H., \& Zheng, J. (2011). Effects of non-wingate-based high-intensity interval trainıng on cardiorespiratory fitness and aerobic-based exercise capacity in sedentary subjects: a prelımınary study, J. Exerc. Sci. Fit., 9(2), 75-81. https://doi.org/10.1016/S1728-869X(12)60001-X 
Vanderthommen, M., \& Duchateau, J. (2007). Electrical Stimulation as a Modality to Improve Performance of the Neuromuscular System. Exercise and Sport Sciences Reviews, 35(4), 180-185. https://doi.org/10.1097/jes.0b013e318156e785

Willardson, J. M. (2007). Core Stability Training: Applications to Sports Conditıoning Programs, Journal of Strength \& Conditioning Research, 21(3).

Zorba, E. (2006). Body Structure Measurement Methods and Fight Against Obesity, 1st. ed., İstanbul, Morpa Kültür Yayınları Lim. Com.

\section{Copyrights}

Copyright for this article is retained by the author(s), with first publication rights granted to the journal.

This is an open-access article distributed under the terms and conditions of the Creative Commons Attribution license which permits unrestricted use, distribution, and reproduction in any medium, provided the original work is properly cited. 